\title{
Supporting and inhibiting factors in recovery experienced by the patients after myocardial infarction during an 18-month follow-up
}

\author{
Olli Oranta, Sinikka Luutonen, Helena Leino-Kilpi \\ Department of Nursing Science, University of Turku, Finland
}

Correspondence: Olli Oranta. Address: University of Turku, Department of Nursing Science and Psychiatric Clinic, Turku University Hospital, Kiinanmyllynkatu 4-8, PL 52, Turku 20521, Finland. Telephone: 358-407-793-137.

Fax: 35-823-138-890. Email: olpeor@saunalahti.fi.

Received: June 3, 2012

Accepted: August 1, $2012 \quad$ Published: February 1, 2013

DOI : $10.5430 /$ jnep.v3n2p19

URL: http://dx.doi.org/10.5430/jnep.v3n2p19

\begin{abstract}
Objective: There is a need for studies on recovery as experienced by the patient after myocardial infarction. This study is a report on supporting and inhibiting factors in recovery of Finnish patients after myocardial infarction in an Interpersonal Counselling intervention group and in a control group given standard care at 6 months and 18 months after myocardial infarction.

Methods: Firstly, during the 6 months following patients receiving IPC $(n=21)$ and standard care $(n=19)$ kept diaries related to supporting and inhibiting factors in recovery. The data were analyzed by inductive content analysis. Secondly, the patients (44 in the intervention group and 42 in the control group) were interviewed with the same open-ended questions 18 months after myocardial infarction. This data were analyzed using deductive content analysis. An attribution analysis was performed on both data.

Results: Five main categories, including supporting and inhibiting factors and subcategories, were identified: (1) clinical and physical, (2) psychological, (3) social, (4) functional and (5) professional. There were no differences between the groups.

Conclusions: Recovery experienced by the patient after myocardial infarction seems to consist of many supporting and inhibiting factors. This is important to take into account in developing nursing practice. The topic calls for more specific studies. These results could be useful material in developing and testing a quantitative instrument for more precise measuring of recovery after MI in a randomized setting. To develop theory, the results indicate numerous possibilities to test relationships between supporting and inhibiting factors in recovery after myocardial infarction.
\end{abstract}

\section{Key words}

Myocardial infarction patient, Recovery experienced by the patient, Nursing practice, Counselling

\section{I ntroduction}

Coronary artery disease, including myocardial infarction has been recognized as a major public health problem worldwide ${ }^{[1]}$. Myocardial infarction (MI) is challenging for nursing practice, as it causes many different kinds of stress 
and distinctive experiences for individual patients, who use different coping strategies in recovery ${ }^{[2,3]}$. The studies of recovery have concentrated more on factors related to morbidity and mortality than on the wider experience of the patient ${ }^{[4,5]}$. Our main interest in this study was to gain a deeper understanding of the supporting and inhibiting factors in recovery among Finnish patients after $\mathrm{MI}$ in an intervention trial ${ }^{[6]}$ that also focused on depression. However, if any differences were found in recovery between the groups, the result would indicate new topics for further research. Health care professionals have recognized the necessity of interventions in general after $\mathrm{MI}^{[5,7]}$ and for concentrating on anxiety and depression, which have strong negative effects on recovery after $\mathrm{MI}^{[8]}$.

\section{Background}

Supporting factors reported by the patients recovering after MI and coronary artery disease include both personal factors and external support ${ }^{[2,9-15]}$. Besides good physical health, various psychological factors have been reported to be supportive after MI. These factors relate to a positive and optimistic attitude or frame of mind ${ }^{[10,14]}$, while resources that help patients accept the disease also seem to support recovery after MI ${ }^{[12]}$. In addition, a variety of personal coping strategies have been reported ${ }^{[11-15]}$. Supporting external factors include helpful interpersonal relations and concrete practical help from family, friends and professionals ${ }^{[2,9,11,16]}$.

Inhibiting factors in recovery after MI are related to supporting factors, but more reports have considered physical health

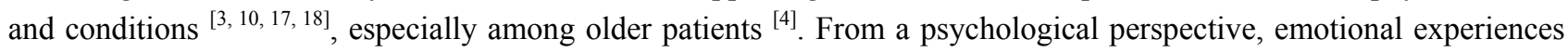
such as fear of dying, emotional distress, family turmoil and existential threat, confusion, and sadness may inhibit recovery ${ }^{[2-4,18,19]}$. Difficulties and sorrows related to social relationships ${ }^{[2-4,12,18]}$ and work ${ }^{[19]}$ have also been reported as inhibiting factors in recovery. In addition, difficulties and criticism against the treatment and the care system have been presented in recovery after $\mathrm{MI}^{[2,14,19]}$.

Stress, depression, and emotional turmoil relate to MI, broadly deteriorating individuals' recovery ${ }^{[4,17,18,20,21]}$. In addition, emotional distress affects both MI survivors and their spouses and intimates ${ }^{[2,3]}$. However, there is a gap between traditional MI rehabilitation programs and needs from the patient's point of view ${ }^{[22]}$. More emphasis should be put on secondary care after MI, as complex barriers related to service-related training and weak communication between primary and secondary care have been reported ${ }^{[19,23]}$. The process of recovery after MI seems to be critical and vulnerable during the first weeks after MI, when psychological care, information, follow-up, and support are especially needed and should be offered ${ }^{[24-26]}$. Care after MI should provide opportunities for patients to talk about their experiences individually ${ }^{[27]}$.

Counselling interventions immediately after MI to prevent cardiac invalidism have been recognized as being important because hospital stays have become shorter ${ }^{[19,28,29]}$. There are some studies, based on patients' experiences, that consider preventive interventions ${ }^{[30]}$ and counselling and rehabilitation after $\mathrm{MI}^{[31]}$ as well as patients' perceptions of post myocardial infarction guidance ${ }^{[32]}$. Beliefs related to the self, illness, cardiac rehabilitation, other attending patients, and the knowledge of health care professionals influence decisions concerning cardiac rehabilitation attendance ${ }^{[31]}$.

One intervention that might positively affect recovery after MI is interpersonal counselling (IPC), which was used in the study. IPC focuses on depressive symptoms, optimism and supporting interpersonal interaction relations ${ }^{[32,34]}$. The main principal idea of IPC is that depressive symptoms relate to interpersonal relations. By having a positive effect on interpersonal relations, it is possible to reduce depressive symptoms in an optimistic and supportive manner. IPC is a briefer version of interpersonal psychotherapy (IPT). It was developed as a time-limited treatment for depression. IPT has been modified to treat different types of mood and non-mood disorders. IPC includes the same principles as IPT, but IPC has shorter and fewer sessions than IPT and is directed at a lower level of symptom severity. IPC is designed for non-psychiatric patients who are in distress, have symptoms related to current stresses in their life, but do not have serious 
concurrent psychiatric disorders or medical conditions ${ }^{[33,34]}$. There are encouraging results in the use of IPT and IPC in practice, for example in the use with elderly patients ${ }^{[35,36]}$.

\section{Methods}

\subsection{Aim}

This study is a report on supporting and inhibiting factors in recovery of Finnish patients after myocardial infarction (MI) in an Interpersonal Counselling (IPC) intervention group and in a control group given standard care at 6 months and 18 months after myocardial infarction (MI).

The research questions were:

1) What are the supporting and inhibiting factors in recovery after MI?

2) How are the supporting and inhibiting factors emphasized?

\subsection{Design}

This article reports on the qualitative part of the main trial, in which the assessments were done in a hospital, at 6 and 18 months after hospital discharge ${ }^{[6]}$. In this study, IPC was administered by a psychiatric nurse who had one day of training in its use. IPC ${ }^{[34]}$ concentrating on interpersonal relations was modified for MI patients and consisted of a starting phase, an encouragement phase, and an ending phase. In the first phase the nurse introduced IPC and the study to the patient. The patients were asked about previous changes in their life circumstances, social functioning and mood, exploring how these circumstances related to the onset of symptoms. During the middle phase the nurse pursued strategies specific to the chosen area: grief, interpersonal role disputes, role transition or interpersonal deficits. In $90.2 \%$ of the cases, the focus was on role transition, including changes in life status after MI. The strategy was then to relate symptoms to difficulties in recovery with previous life changes. The main goals in role transition were such as accepting a new role, seeing it in a more positive light as an opportunity to grow, or perceiving the new role as being less rigorous. In the final phase the patients were counselled in ways of recognizing psychiatric symptoms in the future and on how to go about finding psychiatric help if needed. The role of the intervention nurse was to be active at the beginning, decrease in activity over the course of the sessions and finally to become needless.

Each intervention took from one to six sessions (mean 4.6, Std Dev 1.24, mode 5). At least the first session was arranged in a hospital despite the short duration (3-4 days on average) of hospital treatment in Finland. After hospital discharge, sessions were conducted over the telephone.

\subsection{Participants and sampling}

The participants were both ST-elevation and non-ST-elevation patients with acute MI. All patients under 75 years of age with sufficient knowledge of Finnish were asked to take part in the study. The diagnostic criteria of acute MI required that the patients had to meet the Troponin $\mathrm{T}$ level $\geq 0.03 \mu \mathrm{g} / \mathrm{l}$, and at least one of the three criteria for an acute MI: (1) typical clinical presentation, (2) presence of new ischemic ECG changes, or (3) new diagnostic findings in imaging, e.g. an echocardiogram. MI patients $(\mathrm{n}=103)$ were recruited for the study in one university hospital from September 2004 to January 2007 as part of a larger clinical trial. Patients were randomly placed in a control group $(\mathrm{n}=52)$ or an intervention group $(n=51)$. All patients $(n=103)$ in a larger clinical trial were asked to take part in this study. All patients were given a diary for 6 months (see Figure 1). The diaries were returned six months after discharge by 21 patients $(42.9 \%)$ in the intervention group $(n=49)$ and by 19 patients $(39.6 \%)$ in the control group $(n=48)$. All patients $(n=91)$ were asked to be interviewed 18 months after discharge from the hospital. At 18 months after discharge, 44 patients (91.7\%) in the intervention group $(\mathrm{n}=48)$ and 42 patients $(97.7 \%)$ in the control group $(\mathrm{n}=43)$ were interviewed. 


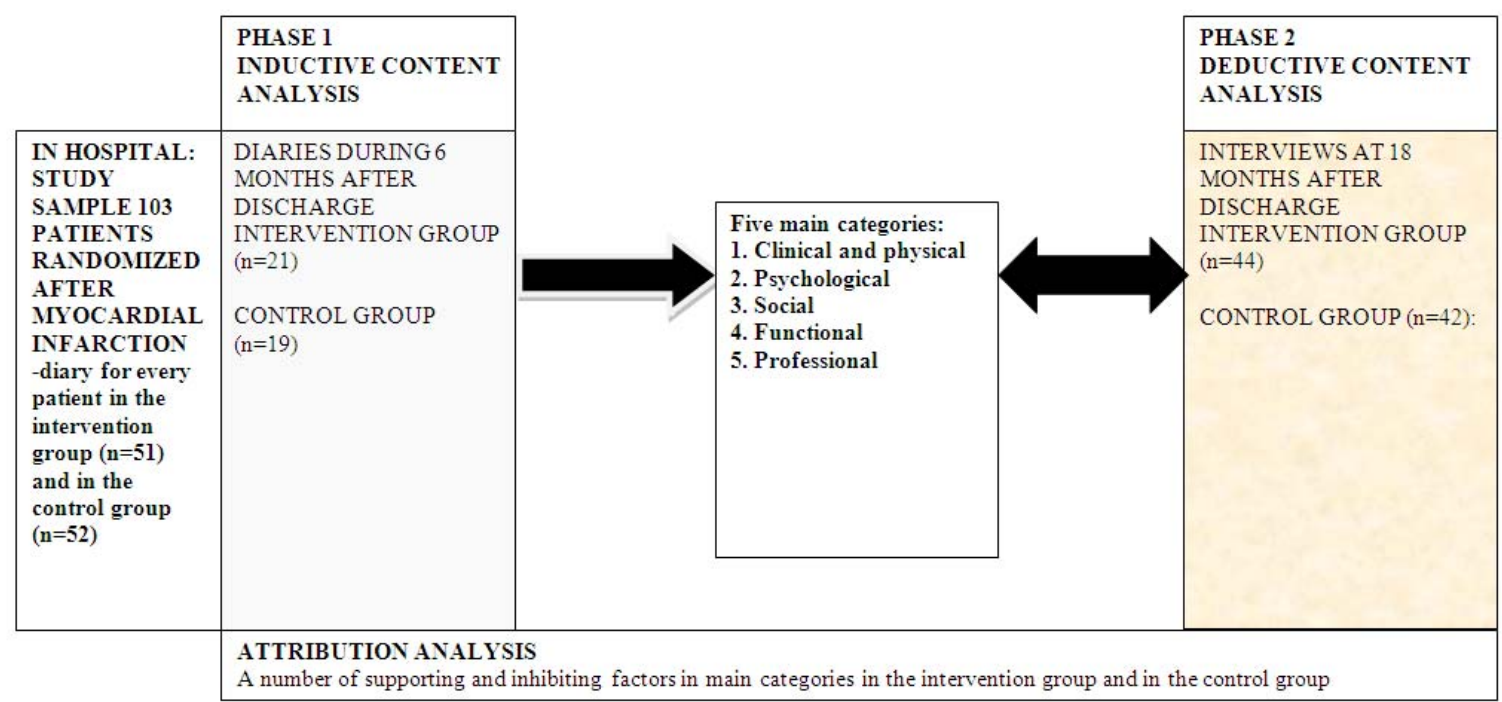

Figure 1. Data collection and design of the study

In the diaries and interviews, the patients first described in general how they recovered after MI. Then the following open-ended questions were asked:

1. What factors supported your recovery after MI?

2. What factors inhibited your recovery after MI?

In the diaries, there were instructions to make notes once a month during the six-month follow-up. The last diary was returned in July 2007. The interviews were performed once in the final phase of the study at 18 months after hospital discharge, in July 2008. The researcher took notes during the telephone interviews.

Inductive ${ }^{[37]}$ and deductive content analysis ${ }^{[38]}$ was used in this study (see Figure 1). Supporting and inhibiting factors in main categories were analyzed by attribution analysis ${ }^{[39]}$ in both phases of the study.

In Phase 1, the content of diaries after 6 months was analyzed using inductive content analysis, including open coding, category creation and abstraction ${ }^{[39,40]}$. The diary notes written by the patients, consisting of 71 pages (A4) of computer-written text (1.5 spacing), were first written into text format at the same time as they were read. The written material was read through repeatedly to examine similarities and differences between expressions used in the text. Meaning units (the constellation of words and statements that related to the same central meaning) ${ }^{[37,39]}$ consisted of a manifestation of the data (answers to the questions). The context of the text resolved the meaning unit. For example, warm weather can be pleasant for taking a walk (functional category) or harmful for breathing (clinical and physical category). A single factor (such as "sense of humor") mentioned several times by a patient was coded only once. However, a patient could report many different factors under one category as being supporting or inhibiting. Five main categories of recovery experienced by the patients were derived from the meaning units. Supporting and inhibiting factors were separated in each main category. In addition, sub-categories were formed by creating tentatively supporting and inhibiting factor gestalts of the central meaning units.

In the second phase, a deductive frame of analysis was used to create structure. Out of the eligible 103 patients during the 18-month follow-up, 6 died and 11 refused the study or could not be reached. The data consisted of the interviews $(\mathrm{n}=86)$ in the intervention group $(n=44)$ and in the control group $(n=42) 18$ months after hospital discharge. The telephone interviews were conducted by the researcher. The data were written down by the researcher and verified by the patients 
during the interview. Also in the second phase, one patient could report many different factors in a single category as supporting or inhibiting, but a single factor could only be reported once. The data were coded in the main categories of supporting and inhibiting factors and additional subcategories. Attribution analysis provides the frequency with which certain characterizations are referred to ${ }^{[39]}$. This was used in both study phases using both data sets to describe the emphasis of supporting and inhibiting factors in the intervention group and in the control group. Supporting and inhibiting factors were revealed in statistical accounts of their contents. The attribution analysis described the frequency of MI patients reporting at least one supporting or inhibiting factor in the main category. The Chi Square test was used to compare differences between the groups. In addition, all references to supporting and inhibiting factors were described both separately in both data sets and combined.

The results of inductive and deductive content analyses were verified by a research group at several meeting controls and by feedback during the study process. Deductive content analysis was used to confirm the structure of the results of the inductive phase. No main or sub-categories were changed in the second phase. The written answers from the interviews were examined again by the researcher to verify the validity of the written text.

\section{Results}

The diaries were completed by $38.8 \%$ of the patients (see Table 1 ). In the interviews ( $n=86$ ) the response rate was $94.5 \%$.

Table 1. Patient characteristics in two phases of the study

\begin{tabular}{|c|c|c|}
\hline Patient Characteristics & Diary $(n=40)$ f $(\%)$ & Interview (n=86) f (\%) \\
\hline \multicolumn{3}{|l|}{ Gender } \\
\hline Male & $22(55.0)$ & $61(70.9)$ \\
\hline Female & $18(45.0)$ & $25(29.1)$ \\
\hline Age: mean, median & $62.5,62.0$ & $59.6,60.0$ \\
\hline$\leq 59$ years & $13(32.5)$ & $37(43.0)$ \\
\hline$\geq 60$ years & $27(67.5)$ & $49(57.0)$ \\
\hline \multicolumn{3}{|l|}{ Retirement } \\
\hline Retired & $27(67.5)$ & $49(57.0)$ \\
\hline Not retired & $13(32.5)$ & $37(43.0)$ \\
\hline \multicolumn{3}{|l|}{ Level of education } \\
\hline No professional education & $18(40.0)$ & $35(40.7)$ \\
\hline Upper secondary education & $12(30.0)$ & $30(34.9)$ \\
\hline College-level education & $7(17.5)$ & $16(18.6)$ \\
\hline University education & $5(12.5)$ & $5(5.8)$ \\
\hline \multicolumn{3}{|l|}{ Other long-term diseases } \\
\hline No other long-term diseases & $14(35.0)$ & $32(37.2)$ \\
\hline At least one long-term disease & $26(65.0)$ & $54(62.8)$ \\
\hline \multicolumn{3}{|l|}{ Previous depression } \\
\hline No previous depression & $31(77.5)$ & $69(80.2)$ \\
\hline At least one depression in a lifetime & $9(22.5)$ & $17(19.8)$ \\
\hline \multicolumn{3}{|l|}{ Depressive symptoms in hospital } \\
\hline No depressive symptoms in hospital $(\mathrm{BDI}<10)$ & $22(55.0)$ & $31(36.1)$ \\
\hline $\begin{array}{l}\text { Depressive symptoms in hospital } \\
(\mathrm{BDI} \geq 10)\end{array}$ & $18(45.0)$ & $55(64.0)$ \\
\hline
\end{tabular}

Five main categories of recovery experienced by the patients were identified during 18 months of follow-up after MI: clinical and physical, psychological, social, functional, and professional categories. In each main category supporting and inhibiting factors and sub-categories were identified. In addition, the differences in supporting and inhibiting factors 
between the intervention group and the control group were measured in the main categories. The next section presents the results of the research questions.

\subsection{Supporting and inhibiting factors in recovery experienced by patients after $\mathrm{MI}$ : the main categories with supporting and inhibiting factors and sub-categories}

The clinical and physical category included both individual experiences and diagnosed conditions and factors reported by the patients. Clinical and physical factors were linked together due to their close interaction in recovery. Among supporting factors (see Table 2), the following sub-categories were analyzed: "Heart convalescence", "No other diseases and symptoms", and "Beneficial physical environment". "Heart convalescence" included supporting factors related to MI and the heart and health in general. "No other diseases and symptoms" consisted of absence and better condition related to other diseases and symptoms. "Beneficial physical environment" included such factors as "milder weather" belonging to this category when they showed up in this context and might influence the patient's clinical and physical condition. All examples from diaries illustrate typical and representative supporting and inhibiting factors in the main categories.

Table 2. Sub-categories of main categories, with examples of supporting and inhibiting factors

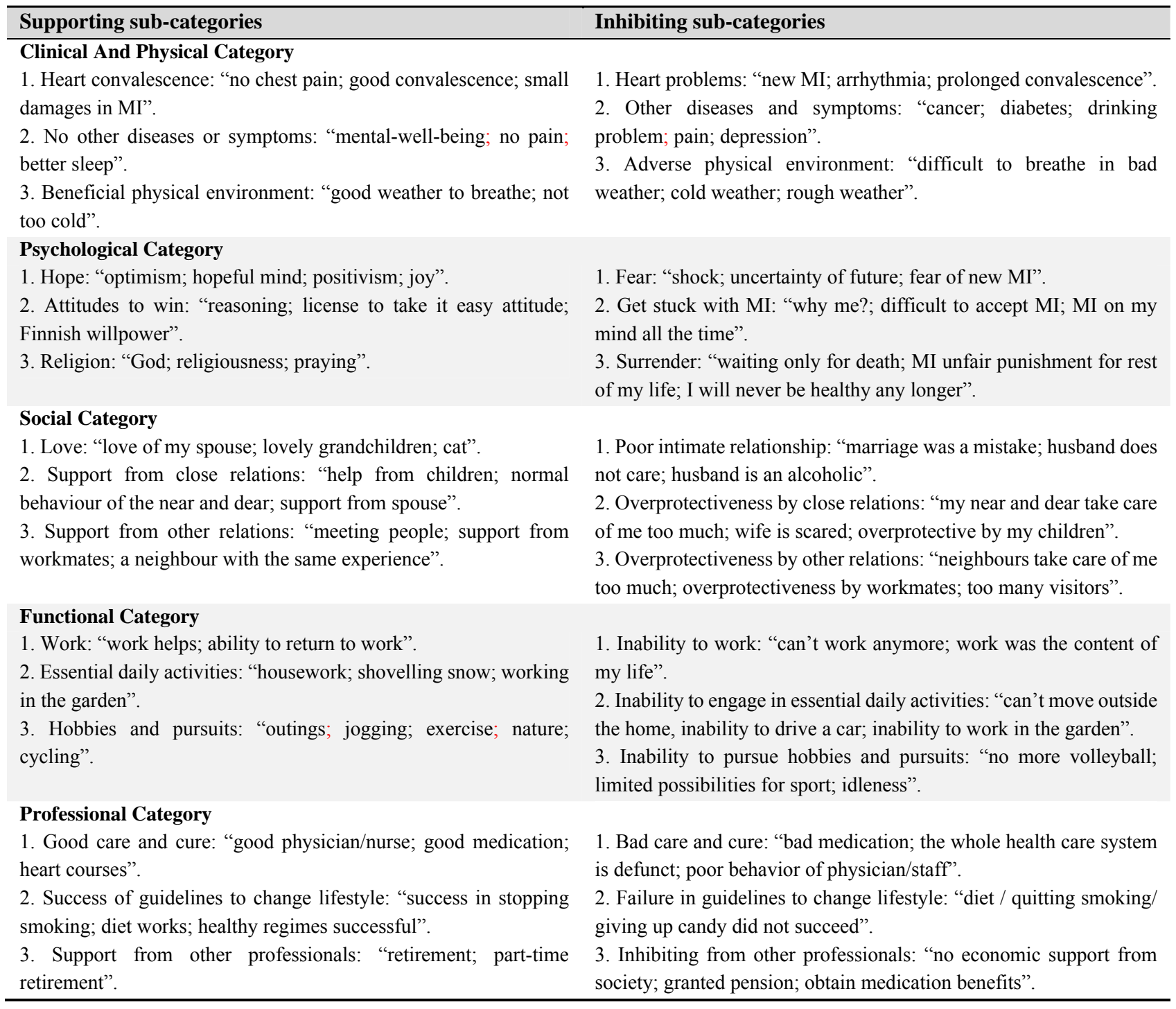


"Heart problems" as an inhibiting sub-category consisted of different kinds of heart problems of varying severity. Factors such as "depression", "anxiety" or "fatigue" (which appeared in the context of clinical or physical factors) belong to the sub-category "Other diseases and symptoms" (which consisted of a number of diseases and symptoms). "Adverse physical environment" included inhibiting factors related to physical and clinical condition. There were more inhibiting factors, including many symptoms of MI and coronary disease, but also of many other diseases and symptoms.

The psychological category included important factors for MI patients and their recovery in terms of their psychological meaning for the patients, such as feelings, attitudes and different kinds of personal defences. Supporting factors included factors indicating successful psychological handling of MI reported in many personal ways. The subcategory of "Hope" included hope, its synonyms, and similar positive feelings and attitudes. The boundary between "Hope" and "Winning attitudes" was not always strict. For example, beneficial personal coping strategies and defences such as humor (mentioned many times by those who reported it), sublimation, or reasoning, which appear frequently in a supportive sense, could be used in both contexts. "Winning attitudes" pointed more towards attitudes or a personal decision to overcome MI. "Religion" consisted of religious convictions as factors.

Inhibiting factors in the psychological category were also reported in many personal ways, and the boundaries between the subcategories were not always clear. "Fear" included inhibiting and sometimes primitive reactions and feelings, which made recovery difficult. "Get stuck with MI" consisted of factors that meant slackening and stagnation in the patient. "Surrender" as a sub-category indicated that the patient had given up and did not have enough strength.

The social category included the factors that were important for the patient's recovery in the social context. The supporting sub-categories "Love", "Support of close relations", and "Support of other relations" describe articulate and undisputed essential factors. "Love" included intimate relationships, in which love and affection was present. Pets, which were especially important for those who lived alone, were coded in this category. "Support of close relations" included more practical help and support from close relations such as family members, which was often highly valued, while "Support of other relations" referred to help and support from other relations, such as friends at work.

Inhibiting factors, which were reported less frequently, were also articulate and undisputed. "Poor intimate relationship" included factors that were often long-term and had emerged before MI, usually being difficulties in marriage or in other intimate relationships. Overprotectiveness and reactions to MI that were somehow unnatural in close or other relations are highlighted in the subcategories "Overprotectiveness of close relations" and "Overprotectiveness of other relations".

The functional category included work, daily activities, pursuits, hobbies (for example nature, seasons, weather, or birds in this context), and various chores. Supporting subcategories were clear in the classification of reported factors. "Work" as a subcategory included just work or job, which many participants reported as being supportive. "Essential daily activities" consisted of everyday chores, housework, or activities considered to be important. "Hobbies and pursuits" consisted of many different factors, often reported to be possible and following factors from other categories, such as "license for taking it easy", pension, or sick leave.

All of the sub-categories ("Inability to work", "Inability to engage in essential daily activities", and "Inability to pursue hobbies and pursuits") consisted of the same factors as the supporting sub-categories, but inability was predominant as being inhibiting.

The professional category included care, cure, and guidelines, which had been provided by all the professionals involved and not only the health care professionals. The data often indicated strong and long-term experience with supporting or inhibiting factors in this category. The supporting sub-category "Good care and cure" included health care staff and their action. "Success in guidelines to change lifestyle" consisted of success in lifestyle changes, such as smoking cessation or diet. "Support from other professionals" included support from without health care. 
In the professional category, the inhibiting subcategories of "Bad care and cure", "Failure in guidelines to change lifestyle" and "Inhibiting from other professionals" were associated with the same factors as the supporting sub-categories. After MI, patients could be dissatisfied with factors related to care and cure, guidelines for changing lifestyles and other factors related to professionals.

\subsection{The emphasis of supporting and inhibiting factors on recovery after MI}

In the attribution analysis, a number of supporting and inhibiting factors were quantified in the intervention group and the control group (see Table 3). In the results of the attribution analysis of diaries during the 6-month follow-up and interviews 18 months after hospital discharge, there were no statistically significant differences between the intervention group and the control group in the number of patients who mentioned at least one factor as supporting or inhibiting for each main category after MI. There were more references to supporting factors than to inhibiting factors in the psychological, social, functional, and professional categories in the two data sets in both groups. The percentage of inhibiting factors was lower in the interviews compared in the diaries in these categories as well. In the clinical and physical category, inhibiting factors made up the majority in both data sets in terms of the number of patients and references.

Table 3. Attribution analysis: Number (\%) of MI patients who reported at least one factor to main categories in two data sets [and the number of all mentions of factors]

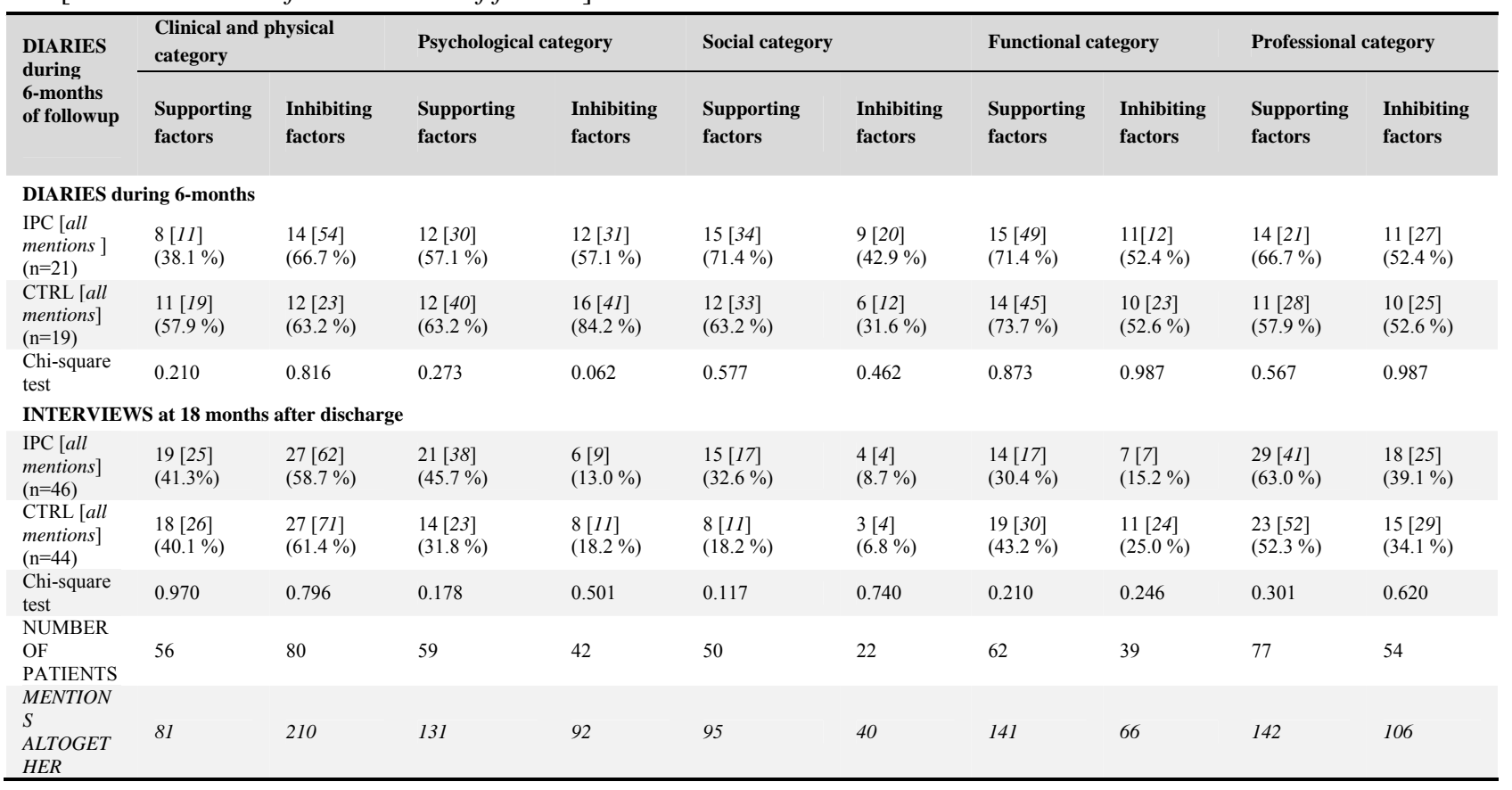

\section{Discussion}

Two qualitative data sets of two groups were analyzed to describe supporting and inhibiting factors after MI in Finland. Five main categories in recovery experienced by the patients after MI were identified: (1) clinical and physical, (2) psychological, (3) social, (4) functional, and (5) professional. The results of previous studies that have reported (for example) problems with convalescence ${ }^{[4]}$, emotional distress ${ }^{[19]}$, the importance of social relations ${ }^{[18]}$, the significance of physical activities ${ }^{[4]}$, and the importance of activity and knowledge from health care services ${ }^{[16]}$ have been confirmed by the results of this study. The results that were similar in the data of diaries and interviews identified as supporting and inhibiting factors in every five main categories. The results of this study build a comprehensive picture of recovery after MI in Finland and they are in line with results of many studies in western countries. 
The sub-categories clarify on a more concrete level just how complicated a phenomenon recovery experienced by patients after MI is. Recovery experienced by the patients consisted of many supporting and inhibiting factors of various kinds. The patients had many diseases and different symptoms during the 18-month follow-up, even though many were still working (mean age 59.6 years at baseline). Co-operation and consultations between different health care providers is an important area in need of continuous development, since psychological aspects are important for individuals in holistic care as well as recovery. The psychological aspects are important for individuals in recovery. In the psychological category, many factors and the sub-categories of "Fear", "Get stuck with MI", and "Surrender" could be changed by psychological intervention towards "Hope" or "Winning attitudes" ${ }^{[41]}$, for example. The supporting factors in this category were more conscious than the inhibiting factors. The number of patients reporting inhibiting factors decreased from 6 months to 18 months after hospital discharge. This may indicate the importance of the observation in nursing practice that psychological recovery takes a long time, as has been reported before ${ }^{[6,21]}$. This is also an example of the need for co-operation between MI clinics and psychiatric care providers. The results indicate, that close relatives are very important after MI. Spouses and close relatives must naturally be taken into consideration when implementing care and sharing information, even with a hectic work pace. Considering the number of patients, the importance of functional factors seems to decrease during the recovery process, which may be a result of the recovery itself. Conversely, supporting and inhibiting factors related to health care professionals are still important for patients 18 months after MI. This poses a challenge to the health care system. Individual supporting and inhibiting factors in the professional category may remain in the patients' minds with great significance.

Supporting and inhibiting factors in recovery after MI do not seem to be different between the patients with IPC intervention and patients with standard care. Despite of previously reported positive results ${ }^{[4]}$, IPC is obviously too short-term and superficial to have effect on recovery. Our hypothesis was not that IPC would significantly affect the supporting or inhibiting factors in recovery after MI, but that it might help find some possible guidelines towards improved recovery and topics for more specific studies. The recovery itself includes changes in experiences. In this study, the results of open-ended questions varied among the respondents. Supporting and inhibiting factors could be useful material in building a quantitative instrument for more precise measuring of recovery after MI in a randomized setting. Five main categories with many different supporting and inhibiting factors highlighted some important points for more specific topics for intervention studies. There are many validated questionnaires for psychiatric symptoms or psychological recovery. Factors such as hope or fear after MI could be a topic for further research.

The limitations in qualitative and descriptive study can be examined through trustworthiness, which includes credibility, dependability, and transferability ${ }^{[37]}$. Credibility refers to confidence in how well the data and processes of analysis address the intended focus ${ }^{[38]}$. The results of this study indicated five main categories, consisting of supporting and inhibiting sub-categories and factors. The weight of supporting and inhibiting factors was measured by the number of patients reporting them and by total number of times they were mentioned by the patients, but not in terms of personal meaning for the patients. For example, we do not know whether or not "picking mushrooms" was less important for the individual than "pancreatic cancer", even if the assessment of health care professionals may be guessed. In addition, attribution analysis (including the quantifying of factors as a result of qualitative study) sets limits on statistical testing. However, attribution analysis was useful for clarifying the weight of supporting and inhibiting factors in the intervention group and in the control group. Dependability means the degree to which data change over time, and looking for a way to account for factors of instability and factors of phenomenal or design-induced changes ${ }^{[40]}$. The duration of hospital treatment after MI is very short in Finland, which made it difficult to recruit patients for the study; and the treatment of MI may have transformed and evolved during the long period of data collection. Patients kept diaries for 6 months, which was assessed to be an appropriate time for the demanding and laborious task. It was practical to carry out easy-to-adopt interviews at 18 months after discharge, at the end of the larger trial. Transferability refers to the extent to which the findings can be transferred to other groups or settings ${ }^{[38,40]}$. Only 40 patients out of 103 completed diaries, and this group included more females and highly educated patients than the sample that was interviewed. In addition, the content of the diaries varied more than the written text of the interviews, where the answers were shorter and more reduced. However, 
the results of the interviews ( $\mathrm{n}=86$ ) were similar to the diaries and in the deductive content analysis the structure of the main categories was applicable. The data collection took place near a university hospital in Finland, which limits the transferability of the results. For example, some issues in functional factors (such as "summer cottage" or "chopping wood") are local and not necessarily important for other Europeans, but the sub-categories in the main categories are a lot broader and flexible, and may also be applicable outside of Finland.

\section{Conclusion}

The results indicated that the recovery experienced by patients after MI is multidimensional, consisting of many kinds of supporting and inhibiting factors, which poses challenges to the health care system and nursing practice. On the other hand, in a global perspective, there are many opportunities to improve care after MI. More attention must be paid to counselling and developing care after MI. In today's hurried nursing practice, patients' individual needs should be observed. Furthermore, on an administrative level, the paths of care after myocardial infarction should be developed in an integrated manner in collaboration between different actors: the knowledge of a patient's individual recovery experience must be forwarded from one health service provider to another. A number of supporting and inhibiting factors and supporting and inhibiting sub-categories indicate recovery after MI from the patients' perspective on a concrete level. Detailed and in-depth studies on the main categories are needed to identify issues in need of development in nursing practice. Supporting and inhibiting sub-categories and factors during recovery call for more specific studies to indicate the possibilities and effects of nursing interventions. A new diagnostic instrument for nursing practice would be a research topic of clinical value. Furthermore, more specific research on the results of IPC after MI (and in the context of other somatic diseases) could be beneficial.

\section{Acknowledgments}

This study was supported by the Hospital District of South-Western Finland, University of Turku and Finnish Foundation of Nursing Education.

\section{References}

[1] WHO. The world health report-Health systems financing: the path to universal coverage [Internet]. 2010. Available at: http://www.who.int/whr/2010/en/index.html (20 February 2011, date last accessed).

[2] Stewart M, Davidson K, Meade D, Makrides J. Myocardial infarction: survivors' and spouses' stress, coping, and support. J Adv Nurs. 2000; 31(6): 1351-1360. PMid:10849146 http://dx.doi.org/10.1046/j.1365-2648.2000.01454.x

[3] Webster RA, Thompson DR, Davidson PM. The first 12 weeks following discharge from hospital: the experience of Gujarati South Asian survivors of acute myocardial infarction and their families. Contemp Nurse. 2003; 15(3): 288-299.

PMid:14649533 http://dx.doi.org/10.5172/conu.15.3.288

[4] Dixon T, Lim LL-Y, Powell H, Fisher JD. Psychosocial experiences of cardiac patients in early recovery: a community-based study J Adv Nurs. 2000; 31(6):1368-1375. PMid:10849148 http://dx.doi.org/10.1046/j.1365-2648.2000.01406.x

[5] Buckley T, McKinley S, Gallagher R, Dracup K, Moser DK, Aitken LM. The effect of education and counselling on knowledge, attitudes and beliefs about responses to acute myocardial infarction symptoms. Eur J Cardiovasc Nurs. 2007; 6(2): $105-111$. PMid:16839819 http://dx.doi.org/10.1016/j.ejcnurse.2006.05.005

[6] Oranta O, Luutonen S, Vahlberg T, Salokangas RKR, Leino-Kilpi H. The outcomes of interpersonal counselling on depressive symptoms and distress after myocardial infarction. Nord J Psychiatry Suppl. 2010; 64(2): 78-86.

PMid:19919291 http://dx.doi.org/10.3109/08039480903402227

[7] Mittag O, China C, Hoberg E, Juers E, Kolenda KD, Richardt G, Maurischat C, Raspe H. Outcomes of cardiac rehabilitation with versus without a follow-up intervention rendered by telephone (Luebeck follow-up trial): overall and gender-specific effects. Int $\mathrm{J}$ Rehabil Res. 2006; 29(4): 295-302. PMid:17106345 http://dx.doi.org/10.1097/MRR.0b013e328010ba9a

[8] May HT, Horne BD, Carlquist JF, Sheng X, Joy E, Catinella AP. Depression After Coronary Aretery Disease Is Associated With Heart Failure. J Am Coll Cardiol. 2009; 253(16): 1440-1447. PMid:19371828 http://dx.doi.org/10.1016/j.jacc.2009.01.036 
[9] Bergman E, Berterö C. You can do it if you set your mind to it: a qualitative study of patients with coronary artery disease. J Adv Nurs. 2001; 36(6): 733-741. PMid:1 1903703 http://dx.doi.org/10.1046/j.1365-2648.2001.02040.x

[10] Daly J, Elliot D, Cameron-Traub E, Salamonson Y, Davidson P, Jackson D, Chin C, Wade V. Health status, perceptions of coping, and social support immediately after discharge of survivors of acute myocardial infarction. Am J Crit Care. 2000; 9(1): 62-69. PMid:10631392

[11] Whittemore R, Rankin SH, Callahan CD, Leder MC, Carroll DL. The peer advisor experience providing social support. Qual Health Res. 2000; 10(2): 260-276. PMid:10788287 http://dx.doi.org/10.1177/104973200129118408

[12] Kerr EE, Fothergill-Bourbonais F. The recovery mosaic: Older women's lived experiences after a myocardial infarction. Heart Lung. 2002; 31(5): 355-366. http://dx.doi.org/10.1067/mhl.2002.127939

[13] White J, Hunter M, Holttum S. How do women experience myocardial infarction? A qualitative exploration of illness perceptions, adjustment and coping. Psychol Health Med. 2007; 12(3): 278-288. http://dx.doi.org/10.1080/13548500600971288

[14] Hutton JM, Perkins SJ. A qualitative study of men's experience of myocardial infarction. Psychol Health Med. 2008; 13(1): 87-97. http://dx.doi.org/10.1080/13548500701294549

[15] Mendes B, Roux G, Ridosh M. Phenomenon of inner strength in women post myocardial infarction. Crit Care Nurs Quart. 2010; 33(3): 248-258. PMid:20551739

[16] Jensen BO, Petersson K. The illness experiences of patients after a first time myocardial infarction. Patient Educ Couns. 2003; 51(2): 123-131. http://dx.doi.org/10.1016/S0738-3991(02)00196-9

[17] Ladwig KH, Roll G, Breithardt G, Budde T, Borggrefe M. Post-infarction depression and incomplete recovery 6 months after acute myocardial infarction. Lancet. 1994; 343: 20-23. http://dx.doi.org/10.1016/S0140-6736(94)90877-X

[18] Al-Hassan M, Sagr L. Stress and stressors of myocardial infarction patients in the early period after discharge. J Adv Nurs. 2002; 40(2): 181-188. PMid:12366648 http://dx.doi.org/10.1046/j.1365-2648.2002.02360.x

[19] Robinson KR. Envisioning a network of care for at-risk patients after myocardial infarction. J Cardiovasc Nurs. 1999; 14(1): 75-88. PMid:10533693

[20] Thombs BD, Bass EB, Ford DE, Stewart KJ, Tsilidis KK, Patel U, Fauerbach JA, Bush DE, Ziegelstein RC. Prevalence of depression in survivors of acute myocardial infarction. J Gen Intern Med. 2006; 21(1): 30-38. PMid:16423120 http://dx.doi.org/10.1111/j.1525-1497.2005.00269.x

[21] Ayers S, Copland C, Dunmore E. A preliminary study of negative appraisals and dysfunctional coping associated with post-traumatic disorder symptoms following myocardial infarction. Br J Health Psychol. 2009; 14(3): 459-471. PMid:18789186 http://dx.doi.org/10.1348/135910708X349343

[22] Páquet M, Bolduc N, Xhignesse M, Vanasse A. Re-engineering cardiac rehabilitation programmes: considering the patient's point of view. J Adv Nurs. 2005; 51(6): 567-576. PMid:16129007

[23] O’Driscoll JM, Shave R, Cushion CJ. A National Health Service Hospital's cardiac rehabilitation programme: a qualitative analysis of provision. J Clin Nurs. 2007; 16(10): 1908-1918. PMid:17880480 http://dx.doi.org/10.1111/j.1365-2702.2007.01815.x

[24] Riegel B. Contributors to cardiac invalidism after acute myocardial infarction. Coron Artery Dis. 1993; 4(2): $215-220$. PMid:8269214 http://dx.doi.org/10.1097/00019501-199302000-00013

[25] Lau-Walker M. Relationship between illness representation and self-efficacy. J Adv Nurs. 2004; 48(3): $216-225$. PMid:15488035 http://dx.doi.org/10.1111/j.1365-2648.2004.03190.x

[26] Hanssen TA, Nordrehaug JE, Hanestad BR. A qualitative study of the information needs of acute myocardial infarction patients, and their preferences for follow-up contact after discharge. Eur J Cardiovasc Nurs. 2005; 4(1): 37-44. PMid:15718191 http://dx.doi.org/10.1016/j.ejcnurse.2004.11.001

[27] Hogg NM, Garratt W, Tagney J. It has certainly been good just to talk an interpretative phenomenological analysis of coping with myocardial infarction. Br J Health Psychol. 2007; 12(4): 651-662. PMid:17535496 http://dx.doi.org/10.1348/135910707X184770

[28] Riegel B, Dracup K. Social support and cardiac invalidism following acute myocardial infarction. Heart Lung, $1992 ; 21: 529-535$. PMid:1446999

[29] Fang J, Alderman MH, Keenan NL, Ayala C. Acute myocardial infarction hospitalization in the United States, 1979 to 2005. Am J Med. 2010; 123: 259-266. PMid:20193835 http://dx.doi.org/10.1016/j.amjmed.2009.08.018

[30] Wright FI, Wiles RA, Mohler M. Patients' and practice nurses' perceptions of secondary preventive care for established ischaemic heart disease: a qualitative study. J Clin Nurs. 2001; 10(2): 180-188. PMid:11820338 http://dx.doi.org/10.1046/j.1365-2702.2001.00469.x

[31] Clark AM, Barbour RS, White M, MacIntyre PD. Promoting participation in cardiac rehabilitation: patient choices and experiences. J Adv Nurs. 2004; 47(1): 2004. PMid:15186462 http://dx.doi.org/10.1111/j.1365-2648.2004.03060.x

[32] Tamada P, Holmes V. Understanding the experience: patients' perceptions of postmyocardial infarction teaching. Prog Cardiovasc Nurs.1998; 13(4): 3-12. 
[33] Markowitz JC. Evidence-based psychotherapies for depression. Occup and Enviromen Med. 2008; 50(4): $437-440$. PMid:18404016 http://dx.doi.org/10.1097/JOM.0b013e318168f76e

[34] Weismann MM, Markowitz JC, Klerman GL. Comprehensive Guide to Interpersonal Psychotherapy. Basic Books. New York: A Member of the Perseus Books Group. 2000.

[35] Miller MD, Wolfson L, Frank E, Cornes C, Silberman R, Ehrenpreis R, Zaltman J, Malloy J, Reynold CF. Using Interpersonal Psychotherapy (IPT) in a Combined Psychotherapy / Medication Research Protocol with Depressed Elders: A Descriptive Report with Case Vignettes. J Psychother Pract Res. 1998; 7: 47-55.

[36] Mossey JM, Knott KA, Higgins M, Talerico K. Effectiveness of a psychosocial intervention, interpersonal counseling, for subdysthymic depression in medically ill elderly. J Gerontol A Biol Sci Med Sci.1996; 51(4): 172-178. http://dx.doi.org/10.1093/gerona/51A.4.M172

[37] Graneheim UH, Lundman B. Quality content analysis in nursing research: concepts, procedures and measures to achieve trustworthiness. Nurse Education Today. 2004; 24(2): 105-112. PMid:14769454 http://dx.doi.org/10.1016/j.nedt.2003.10.001

[38] Polit DF, Hungler BP. Nursing Research. Principles and Methods, sixth ed. J.B. Lippincott Company, Philadelphia, New York, Baltimore; 1999.

[39] Krippendorff K. Content Analysis: An introduction to its methodology. Edition 2. SAGE. 2004.

[40] Lincoln YS, Guba EG. Naturalistic Inquiry. Sage Publications Inc., Newbury Park, London, New Delhi. 1985.

[41] Kylmä J, Turunen H, Perälä M-L. Hope and cchronic illness: The meaning of hope and the ways of fostering hope experienced by chronically ill Finnish people. Int J Nurs Pract; 2(4): 209-214. 